\title{
PLASMA TRANSPORT IN THE TOPSIDE VENUS IONOSPHERE
}

\author{
R. W. SCHUNK \\ Center for Research in Aeronomy, Utah State University, Logan, UT 84322, U.S.A. \\ and \\ J.-P. ST,-MAURICE \\ Department of Atmospheric and Oceanic Science, The University of Michigan, Ann Arbor, MI 48109, U.S.A.
}

(Received 14 March 1977)

\begin{abstract}
We have studied the extent to which certain transport processes affect ion composition and heat flow in the daytime, topside Venus ionosphere. Particular attention is given to the conditions that prevailed during the Mariner 5 measurements, at which time the topside Venus ionosphere appeared to be in a state of diffusive equilibrium. We have found that the ion composition is sensitive to the ion temperature, the ion temperature gradient, and to relative drifts between the ion species of a few $\mathrm{m} / \mathrm{sec}$. The electron density, on the other hand, is very insensitive to these parameters. As a consequence, ionospheric models of the topside Venus ionosphere are not likely to yield definitive information about the ion composition, the thermal structure or the flow conditions, since at present only electron density profiles are available for testing model predictions. We have also found that a relative drift between the ion species of a few $\mathrm{m} / \mathrm{sec}$ induces an ion heat flow that is equivalent to a $1 \mathrm{~K} / \mathrm{km}$ temperature gradient. This induced heat flow could influence the energy balance in the topside Venus ionosphere.
\end{abstract}

\section{INTRODUCTION}

At present, the only substantial information we have about the Venus ionosphere derives from the Mariner 5 and 10 measurements (Kliore et al., 1967; Eshleman et al., 1967; Howard et al., 1974; Fjeldbo et al., 1975). At the times of the two measurements, however, there was a significant difference in the structure of the dayside Venus ionosphere. The electron density profile observed by Mariner 10 has two distinct ledges, one near $180 \mathrm{~km}$ and the other near $250 \mathrm{~km}$, while the Mariner 5 profile does not exhibit pronounced ledges. Furthermore, the electron density scale height in the topside ionosphere appears to be that appropriate to diffusive equilibrium for Mariner 5, while large upward or downward flow velocities are needed to explain the Mariner 10 topside electron density scale height (Bauer and Hartle, 1974; Nagy et al., 1975). The difference between the Mariner 5 and 10 dayside ionosphere is undoubtedly due to a solar wind-ionosphere interaction mechanism (Bauer and Hartle, 1974). At the time of the Mariner 5 measurement, the ionopause was located at about $500 \mathrm{~km}$, while for Mariner 10 it was at approximately $350 \mathrm{~km}$.

There have been a number of theoretical models of the daytime Venus ionosphere (McElroy, 1968; McElroy and McConnell, 1971; Herman et al., 1971; Kumar and Hunten, 1974; Bauer and Har- tle, 1974; Nagy et al., 1975). In the early models, the neutral exospheric temperature was taken to be $700 \mathrm{~K}$, while in the more recent models of Kumar and Hunten (1974), Bauer and Hartle (1974) and Nagy et al. (1975) a $350 \mathrm{~K}$ exospheric temperature was adopted. As far as the charged particle temperatures are concerned, the various models cover a range of adopted ion and electron temperature profiles. For example, Nagy et al. (1975) set $T_{i}=$ $350 \mathrm{~K}$ at all altitudes above about $160 \mathrm{~km}$, while Kumar and Hunten (1974) assumed that $T_{i}=$ $1500 \mathrm{~K}$. The difficulty with the charged particle temperatures is that there are no direct experimental data on electron or ion temperatures in the Venus ionosphere. At present, only the theoretical calculations of Whitten (1969), Herman et al. (1971) and McCormick et al. (1976) are available as a guide to the thermal structure of the Venus ionosphere. These calculations indicate that significant differences between neutral, ion, and electron temperatures are possible in the topside Venus ionosphere and that appreciable ion and electron temperature gradients are also possible. However, the magnitudes of the theoretical temperatures are uncertain, because the different authors assumed different boundary conditions and different ionospheric models.

The recent ionospheric models of Kumar and Hunten (1974) and Nagy et al. (1975) yield a 
different major ion above $220 \mathrm{~km}$, despite similar chemical reaction schemes. In the Kumar and Hunten (1974) model, $\mathrm{O}^{+}$is the major topside ion, while in the Nagy et al. (1975) model $\mathrm{O}_{2}{ }^{+}$is the major ion. In both models, the ions are in diffusive equilibrium above $200 \mathrm{~km}$.

We have recently derived diffusion and heat flow equations for a gas mixture composed of two major ions, electrons and a number of minor ions (St.Maurice and Schunk, 1977). These equations were derived from the 13-moment system of transport equations presented by Schunk (1975) with the assumption that the species temperature and drift velocity differences were small. The new equations therefore appear to be applicable to the topside Venus ionosphere for the conditions occurring at the time of the Mariner 5 daytime measurements.

Using the new transport equations, we have studied the extent to which various transport processes affect the structure of the topside Venus ionosphere $(200-400 \mathrm{~km})$. Because of the uncertainty in the thermal structure of the Venus ionosphere, we have considered a couple of base ion temperatures and several ion and electron temperature gradients. We have also considered relative flows between the dominant ions. For the ion densities at our lower boundary $(200 \mathrm{~km})$, we have adopted the $\mathrm{CO}_{2}{ }^{+}, \mathrm{O}_{2}{ }^{+}$and $\mathrm{O}^{+}$densities calculated by Nagy et al. (1975).

In Section 2, we present the diffusion and heat flow equations and briefly discuss some of the new transport terms. In Section 3, we present ion and electron density profiles corresponding to Mariner 5 conditions, and we discuss the possible importance of induced ion heat flow due to a relative drift between the dominant ion species. Section 5 contains our summary.

\section{THEORX}

The recent ionospheric models of Kumar and Hunten (1974) and Nagy et al. (1975) clearly indicate that transport is more important than chemistry at altitudes above about $190 \mathrm{~km}$. We have also found that at these altitudes the plasma is effectively fully-ionized. This is shown in Table 1, where we compare the Coulomb collision frequencies with the ion-neutral collision frequencies for the ionospheric model considered by Nagy et al. (1975). The $\mathrm{CO}_{2}, \mathrm{CO}$ and $\mathrm{O}$ densities needed in the calculation of the ion-neutral collision frequencies were extrapolated from the values given by Liu and Donahue (1975) with an exospheric temperature of $350 \mathrm{~K}$. The comparison shown in Table 1 clearly indicates that above $200 \mathrm{~km}$ Coulomb collisions are more
TABle 1. Comparison of ION-NEUTRAL AND Coulomb COLLISION FREOUENCIES

\begin{tabular}{|c|c|c|c|c|c|c|}
\hline \multirow{2}{*}{$\begin{array}{l}\text { Alti- } \\
\text { tude } \\
\text { (km) }\end{array}$} & \multicolumn{3}{|c|}{ Ion-neutral $\left(\mathrm{sec}^{-1}\right)$} & \multicolumn{3}{|c|}{ Coulomb $\left(\mathrm{sec}^{-1}\right)$} \\
\hline & $\mathrm{O}^{+}$ & $\mathrm{CO}_{2}{ }^{+}$ & $\mathrm{O}_{2}^{+}$ & $\mathbf{O}^{+}$ & $\mathrm{CO}_{2}{ }^{+}$ & $\mathrm{O}_{2}^{+}$ \\
\hline $\begin{array}{l}200 \\
220 \\
240 \\
260 \\
280 \\
300 \\
320 \\
340 \\
360 \\
380 \\
400\end{array}$ & $\begin{array}{l}3.0(-2)^{*} \\
5.3(-3) \\
1.6(-3) \\
5.7(-4) \\
2.3(-4) \\
9.2(-5) \\
3.7(-5) \\
1.5(-5) \\
6.4(-6) \\
2.7(-6) \\
1.1(-6)\end{array}$ & $\begin{array}{l}1.3(-2) \\
1.9(-3) \\
4.6(-4) \\
1.6(-4) \\
6.2(-5) \\
2.5(-5) \\
1.0(-5) \\
4.2(-6) \\
1.7(-6) \\
7.2(-7) \\
3.0(-7)\end{array}$ & $\begin{array}{l}1.7(-2) \\
2.4(-3) \\
6.0(-4) \\
2.1(-4) \\
8.1(-5) \\
3.3(-5) \\
1.3(-5) \\
5.5(-6) \\
2.3(-6) \\
9.5(-7) \\
4.0(-7)\end{array}$ & $\begin{array}{l}1.45 \\
0.89 \\
0.66 \\
0.49 \\
0.37 \\
0.30 \\
0.25 \\
0.21 \\
0.18 \\
0.16 \\
0.14\end{array}$ & $\begin{array}{l}0.70 \\
0.42 \\
0.32 \\
0.23 \\
0.17 \\
0.13 \\
0.11 \\
0.09 \\
0.08 \\
0.07 \\
0.06\end{array}$ & $\begin{array}{l}0.89 \\
0.54 \\
0.40 \\
0.29 \\
0.22 \\
0.17 \\
0.14 \\
0.12 \\
0.10 \\
0.09 \\
0.08\end{array}$ \\
\hline
\end{tabular}

$* 3.0(-2)=3.0 \times 10^{-2}$.

important than ion-neutral collisions, especially for the minor ions.

We have recently derived diffusion and heat flow equations for a fully-ionized multicomponent plasma composed of two major ions, electrons, and a number of minor ions. Letting subscripts $i$ and $j$ correspond to the major ions, subscript $x$ to the minor ion, and subscript $e$ to the electrons, these equations can be expressed in the form:

$$
\begin{aligned}
& u_{i}=a_{i}-D_{i}\left[\frac{1}{n_{i}} \nabla n_{i}-\frac{m_{i} G}{k T_{i}}+\frac{1}{T_{i}} \nabla T_{i}+z_{i} \frac{T d T_{i}}{n_{e}} \nabla n_{i}\right. \\
& \left.+\frac{\left(z_{i}-\gamma_{i}\right)}{T_{i}} \nabla T_{e}+\frac{n_{i}}{n_{i}+n_{i}}\left(\frac{\alpha_{i j}}{T_{i}} \nabla T_{i}-\frac{\alpha_{i j}^{*}}{T_{i}} \nabla T_{i}\right)\right] \\
& n_{j}=u_{i}-D_{i}\left[\frac{1}{n_{i}} \nabla n_{j}-\frac{m_{i} G}{k T_{i}}+\frac{1}{T_{j}} \nabla T_{i}+z_{j} \frac{T d T_{i}}{n_{e}} \nabla n_{e}\right. \\
& \left.+\frac{\left(z_{i}+\gamma_{i}\right)}{T_{i}} \nabla T_{e}-\frac{n_{i}}{n_{i}+n_{i}}\left(\frac{\alpha_{i j}}{T_{i}} \nabla T_{i}-\frac{\alpha_{i j}{ }^{*}}{T_{i}} \nabla T_{i}\right)\right] \\
& \mathbf{u}_{x}=h_{x i} \mathbf{u}_{i}+h_{x j} \mathbf{u}_{i} \\
& -D_{x}\left[\frac{1}{n_{x}} \nabla n_{x}-\frac{m_{x} G}{k T_{x}}+\frac{1}{T_{x}} \nabla T_{x}+z_{x} \frac{T_{d} T_{x}}{n_{e}} \nabla n_{e}\right. \\
& \left.+\frac{\left(z_{x}-\gamma_{x}\right)}{T_{x}} \nabla T_{e}-\frac{1}{T_{x}}\left(\beta_{x} \nabla T_{x}+\beta_{i} \nabla T_{i}+\beta_{j} \nabla T_{j}\right)\right] \\
& q_{i}=\frac{1}{1-\xi}\left[-\lambda_{i} \nabla T_{i}-\frac{\rho_{i}}{\rho_{i}} \frac{\nu_{i j}^{\prime}}{\nu_{i}^{\prime}} \lambda_{j} \nabla T_{i}\right. \\
& \left.+\left(\delta_{i j}-\frac{\rho_{i}}{\rho_{i}} \frac{\nu_{i j}^{\prime}}{\nu_{i}^{\prime}} \delta_{i i}\right)\left(\mathbf{u}_{i}-\mathbf{u}_{j}\right)\right]
\end{aligned}
$$




$$
\begin{aligned}
\mathbf{q}_{i}= & \frac{1}{1-\xi}\left[-\lambda_{i} \nabla T_{j}-\frac{\rho_{i}}{\rho_{i}} \frac{\nu_{i i}^{\prime}}{\nu_{i}^{\prime}} \lambda_{i} \nabla T_{i}\right. \\
& \left.+\left(\delta_{i i}-\frac{\rho_{j}}{\rho_{i}} \frac{\nu_{i i}^{\prime}}{\nu_{i}^{\prime}} \delta_{i j}\right)\left(\mathbf{u}_{i}-\mathbf{u}_{i}\right)\right] \\
\mathbf{q}_{x}= & -\lambda_{x} \nabla T_{x}+\frac{\rho_{x} \nu_{x i}^{\prime}}{\rho_{i} \nu_{x}^{\prime}} \mathbf{q}_{i}+\frac{\rho_{x} \nu_{x i}^{\prime}}{\rho_{i} \nu_{x}{ }^{\prime}} \mathbf{q}_{i} \\
& +\delta_{x i}\left(\mathbf{u}_{x}-\mathbf{u}_{i}\right)+\delta_{x j}\left(\mathbf{u}_{x}-\mathbf{u}_{i}\right),
\end{aligned}
$$

where the electron density and drift velocity are obtained from the requirements of charge neutrality and charge conservation, respectively,

$$
\begin{aligned}
n_{e} & =n_{i} z_{i}+n_{j} z_{j} \\
n_{e} \mathbf{u}_{e} & =n_{i} z_{i} \mathbf{u}_{i}+n_{j} z_{j} \mathbf{u}_{j} .
\end{aligned}
$$

In equations (1)-(8), $n_{i}$ is the density of ion species $i, m_{i}$ is the mass, $T_{i}$ is the temperature, $z_{i}$ is the ion charge number, $\rho_{i}=n_{i} m_{i}$ is the mass density, ${\boldsymbol{m}_{i}}_{i}$ is the drift velocity, $q_{i}$ is the heat flow vector; $\xi=\nu_{i j}{ }^{\prime} \nu_{i i}{ }^{\prime} /\left(\nu_{i}^{\prime} \nu_{i}^{\prime}\right), \mathbf{G}$ is the acceleration due to gravity, $k$ is Boltzmann's constant, and $\nabla$ is the coordinate space gradient. The quantities $\alpha_{i j}, \alpha_{i j}{ }^{*}, \gamma_{i}$ and $\beta_{i}$ are thermal diffusion coefficients, $D_{i}$ is the ordinary diffusion coefficient, $h_{x i}$ is a frictional drag coefficient, $\lambda_{i}$ is the thermal conductivity, $\delta_{i j}$ is an induced heat flow coefficient, and $\nu_{i}{ }^{\prime}$ and $\nu_{i j}{ }^{\prime}$ are effective collision frequencies. Similar definitions hold for species $j, x$ and $e$. The ordinary diffusion coefficients, thermal diffusion coefficients, frictional drag coefficients, thermal conductivities, induced heat flow coefficients and effective collision frequencies are given by St.-Maurice and Schunk (1977) and will not be repeated here.

Several simplifying assumptions are implicit in the diffusion and heat flow equations. These equations were derived by assuming steady-state $\infty$ nditions, by neglecting stress and non-linear acceleration terms, and by using Burgers' linear collision terms (Burgers, 1969). The use of Burgers' linear collision terms implies small temperature and drift velocity differences between the interacting species.

Equations (1)-(3) can be used to treat a situation in which there is more than one transition region, say from $\mathrm{CO}_{2}^{+}$to $\mathrm{O}_{2}^{+}$, and then from $\mathrm{O}_{2}^{+}$to $\mathrm{O}^{+}$, by redefining the major and minor ions at an altitude which lies between the two transition regions. If the charged particle temperature and flux profiles and the lower boundary ion densities are specified, equations (1)-(3) can be integrated numerically using a Runge-Kutta integration technique to yield altitude profiles of ion density.

\section{TOPSIDE VENUS IONOSPHERE}

To study the ion composition in the topside Venus ionosphere, we solve equations (1)-(3) for daytime steady-state conditions over the altitude range $200-400 \mathrm{~km}$. At these altitudes, the main ions are $\mathrm{CO}_{2}{ }^{+}, \mathrm{O}_{2}^{+}$and $\mathrm{O}^{+}$. For the ion densities at our lower boundary $(200 \mathrm{~km})$, we adopt the values calculated by Nagy et al. (1975) for Mariner 5 conditions; $n\left(\mathrm{CO}_{2}^{+}\right)=7.74 \times 10^{3} \mathrm{~cm}^{-3}, \quad n\left(\mathrm{O}_{2}^{+}\right)=$ $2.78 \times 10^{4} \mathrm{~cm}^{-3}$ and $n\left(\mathrm{O}^{+}\right)=7.94 \times 10^{2} \mathrm{~cm}^{-3}$. These lower boundary values are not changed in any of our models. For most of our calculations, we also adopt the Nagy et al. (1975) electron temperature profile, which is nearly constant between 200 and $400 \mathrm{~km}$ with $T_{e} \approx 2000 \mathrm{~K}$. As in the previous model studies, we neglect horizontal transport.

\section{Effect of ion temperature gradients}

To illustrate the sensitivity of the ion composition to ion temperature, we present in Fig. 1 diffusive equilibrium ion and electron density profiles for several ion temperature profiles covering a range of constant ion temperature gradients. For all three cases, the different ions are assumed to have a common temperature, which increases with altitude from a base value of $350 \mathrm{~K}$ with a gradient of (a) 0 , (b) 3 and (c) $5 \mathrm{~K} / \mathrm{km}$. Also shown in Fig. 1 are the density profiles that result when thermal diffusion effects are neglected. It is apparent that the ion composition is very sensitive to the ion temperature profile. Increasing the ion temperature gradient acts to increase the $\mathrm{CO}_{2}{ }^{+}$and $\mathrm{O}_{2}{ }^{+}$densities and reduce the $\mathrm{O}^{+}$density at all altitudes above $200 \mathrm{~km}$. This behaviour is enhanced by thermal diffusion, which becomes important for ion temperature gradients greater than about $3 \mathrm{~K} / \mathrm{km}$. The increase in the molecular ion densities coupled with the reduction in the $\mathrm{O}^{+}$density acts to increase significantly the $\mathrm{O}_{2}^{+} / \mathrm{O}^{+}$transition altitude, which increases from 280 to greater than $400 \mathrm{~km}$ as $\nabla T_{i}$ increases from 0 to $5 \mathrm{~K} / \mathrm{km}$.

Although there is a significant change in the ion composition as the gradient in the ion temperature increases, there is a very small change in the electron density profile. Further model calculations, which are described below, covering the same range of ion temperature gradients but for a greater base ion temperature yield the same result. Therefore, if the ion temperature in the topside Venus ionosphere is less than or comparable to the electron temperature, as assumed in all of our models, our results indicate that the Mariner 5 electron density profile cannot yield definitive information on the ion temperature gradient. 

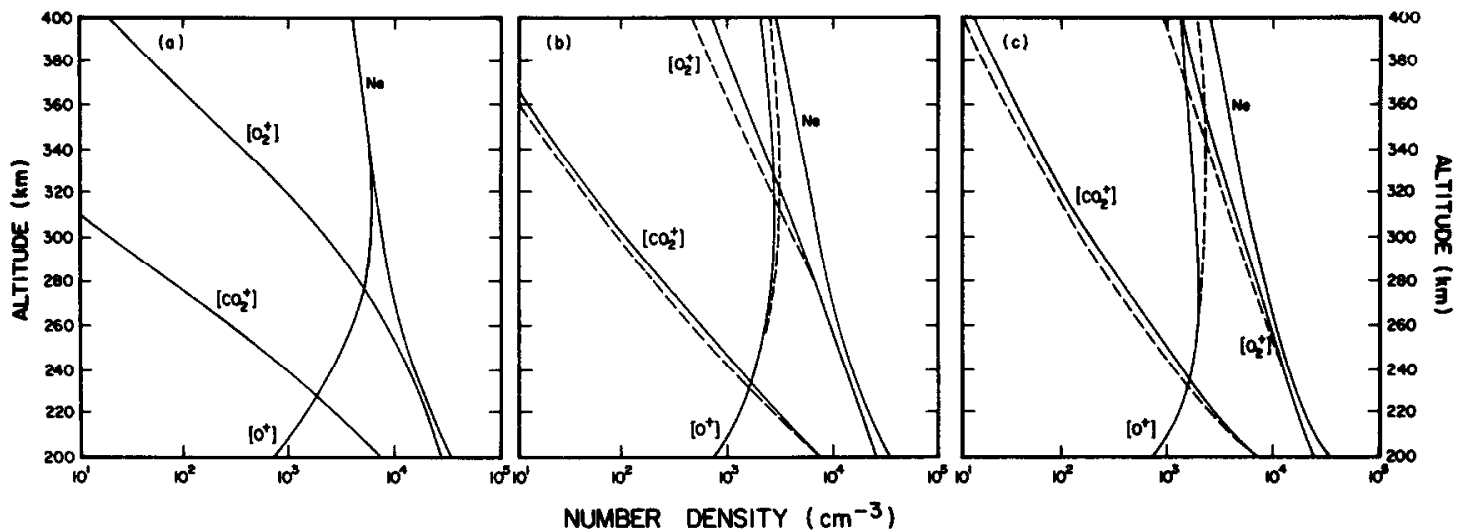

Fig. 1. ION AND ELECTRON DENSITY PROFILES FOR SEVERAL CONSTANT ION TEMPERATURE GRADIENTS AND FOR A LOWER BOUNDARY ION TEMPERATURE OF $350 \mathrm{~K}$.

The ion temperature gradients are: (a) 0 , (b) 3 and (c) $5 \mathrm{~K} / \mathrm{km}$. The dashed curves show the density profiles calculated without allowance for the effects of thermal diffusion.

In Fig. 2, we present ion and electron density profiles for the same conditions that led to Fig. 1, except that the lower boundary ion temperature, $T_{B}$, is now set equal to $700 \mathrm{~K}$. The comparison of Figs. 1(a) and 2(a) illustrates the effect on the ion composition of an enhanced, uniform ion temperature. An increase in the uniform ion temperature from 350 to $700 \mathrm{~K}$ results in a significant composition change, with the molecular ion densities increased and the $\mathrm{O}^{+}$density reduced at all altitudes. As a result of this change, the $\mathrm{O}_{2}{ }^{+} / \mathrm{O}^{+}$transition altitude is increased from 280 to $360 \mathrm{~km}$. Although there is a significant composition change, there is a negligibly small difference between electron density profiles.
As with $T_{B}=350 \mathrm{~K}$, an increase in the ion temperature gradient acts to increase $\mathrm{CO}_{2}^{+}$and $\mathrm{O}_{2}^{+}$ densities and reduce the $\mathrm{O}^{+}$density at all altitudes. However, the change in the ion density profiles for a given ion temperature gradient is not as large for $T_{B}=700 \mathrm{~K}$ as for $T_{B}=350 \mathrm{~K}$. Furthermore, although thermal diffusion is important for $T_{B}=$ $350 \mathrm{~K}$ and $\nabla T_{i}>3 \mathrm{~K} / \mathrm{km}$, it has a negligibly small effect on the profiles for $T_{B}=700 \mathrm{~K}$ for the three temperature gradients considered.

Effect of separate temperature gradients for the different ions

In Figs. 3 and 4 we show the effect on the ion composition of separate temperature gradients for
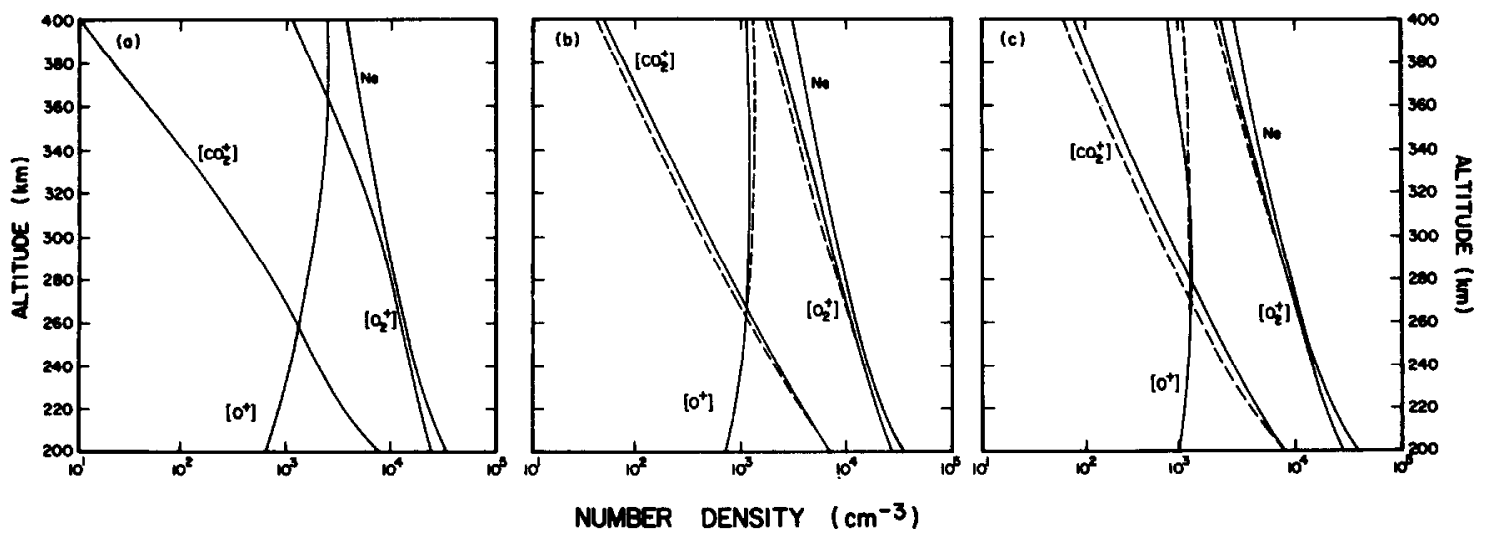

FIG. 2. IUN AND ELECTRON DENSITY PROFILES FOR SEVERAL CONSTANT ION TEMPERATURE GRADIENTS AND FOR A LOWER BOUNDARY ION TEMPERATURE OF $700 \mathrm{~K}$.

The ion temperature gradients are: (a) 0 , (b) 3 and (c) $5 \mathrm{~K} / \mathrm{km}$. The dashed curves show the density profiles calculated without allowance for the effects of thermal diffusion. 

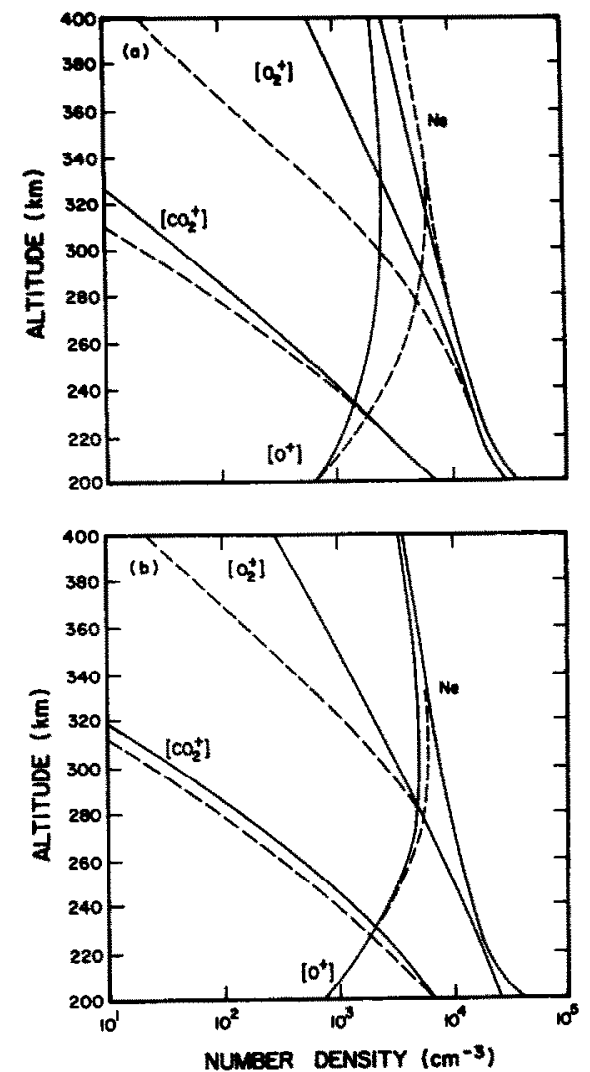

FIG. 3. ION AND ELECTRON DENSTTY PROFLlES FOR THE CASE WHERE THE DIFFERENT ION SPECIES HAVE DIFFERENT BUT CONSTANT ION TEMPERATURE GRADIENTS AND FOR A BASE ION TEMPERATURE OF $350 \mathrm{~K}$.

For the top figure, the $\mathrm{O}^{+}, \mathrm{O}_{2}^{+}$and $\mathrm{CO}_{2}^{+}$temperature gradients are 3,1 and $0 \mathrm{~K} / \mathrm{km}$, respectively, while for the bottom figure the gradients are 1,3 and $0 \mathrm{~K} / \mathrm{km}$, respectively. The dashed curves show the density profiles that result when the different ion temperature gradients are set equal to zero.

the different ion species. For Fig. 3 the ions have a common base temperature of $350 \mathrm{~K}$, while for Fig. 4 the base temperature is $700 \mathrm{~K}$. For both figures, the top half corresponds to $\mathrm{O}^{+}, \mathrm{O}_{2}{ }^{+}$and $\mathrm{CO}_{2}{ }^{+}$ temperature gradients of 3,1 and $0 \mathrm{~K} / \mathrm{km}$, respectively, while for the bottom half these gradients are 1,3 and $0 \mathrm{~K} / \mathrm{km}$, respectively. Also shown in these figures are the density profiles that result when the different ion temperature gradients are set equal to zero. The behaviour of the ion composition as a function of individual ion temperature gradient is similar to that obtained for a common ion temperature gradient, in that an increase in either the $\mathrm{O}^{+}$or $\mathrm{O}_{2}^{+}$temperature gradient acts to increase the molecular ion densities and reduce the $\mathrm{O}^{+}$density and, hence, acts to increase the $\mathrm{O}_{2}{ }^{+} / \mathrm{O}^{+}$transition altitude. Also, as for a common ion temperature gradient, a given individual ion temperature gradient produces a larger composition change for $T_{B}=350 \mathrm{~K}$ than for $T_{B}=700 \mathrm{~K}$.

A novel feature of the results shown in Figs. 3 and 4 is that a given $\mathrm{O}^{+}$temperature gradient has a much larger effect on the ion composition than does an equivalent $\mathrm{O}_{2}{ }^{+}$temperature gradient. This could be important in the topside Venus ionosphere if the solar wind-ionosphere interaction mechanism of Bauer and Hartle (1974) is operating. These authors suggest that solar wind protons are capable of crossing the ionopause and penetrating to low altitudes. The penetrating solar wind
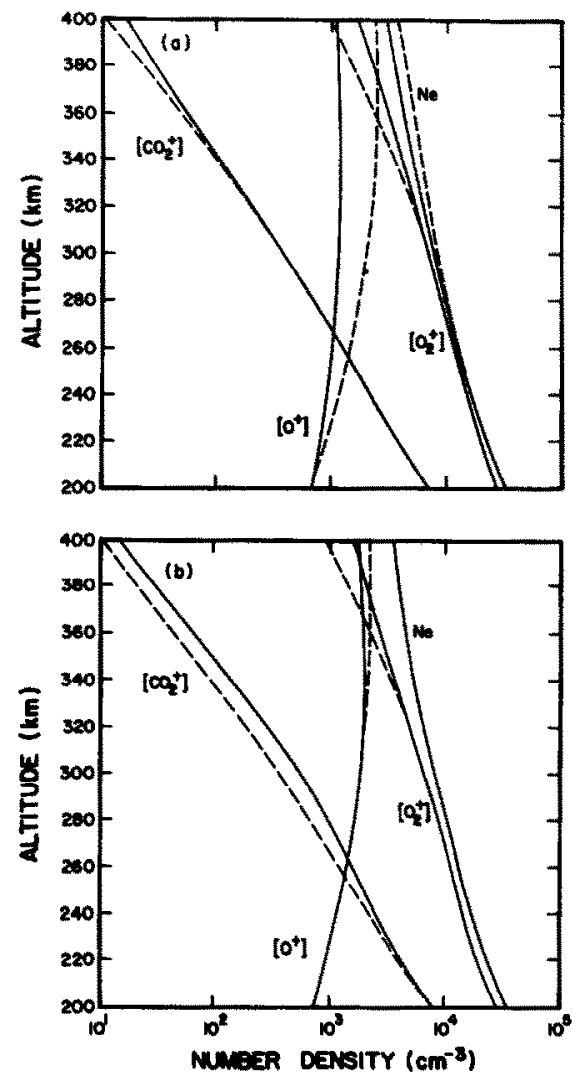

FIG. 4. ION AND ELECTRON DENSTTY PROFILES FOR THE CASE WHERE THE DIFFERENT ION SPECIES HAVE DIFFERENT BUT CONSTANT ION TEMPERATURE GRADIENTS AND FOR A BASE ION TEMPERATURE OF $700 \mathrm{~K}$.

For the top figure, the $\mathrm{O}^{+}, \mathrm{O}_{2}^{+}$and $\mathrm{CO}_{2}{ }^{+}$temperature gradients are 3,1 and $0 \mathrm{~K} / \mathrm{km}$, respectively, while for the bottom figure the gradients are 1,3 and $0 \mathrm{~K} / \mathrm{km}$, respectively. The dashed curves show the density profiles that result when the different ion temperature gradients are set equal to zero. 
protons then transmit energy and momentum to the thermal ions as they are slowed. Because of a more favourable mass ratio, the solar wind protons would exchange energy and momentum more readily with $\mathrm{O}^{+}$than either $\mathrm{O}_{2}{ }^{+}$or $\mathrm{CO}_{2}{ }^{+}$and this, in turn, could result in an elevated $\mathrm{O}^{+}$temperature gradient and a relative drift between $\mathrm{O}^{+}$and the molecular ions. This latter effect is discussed in the next subsection.

Again we note that although there are significant differences in the altitude structure of the ion densities for the various cases shown in Figs. 3 and 4, there is a negligibly small difference between the electron density profiles.

\section{Effect of $\mathrm{O}^{+}$flows}

The ion diffusion equations (1)-(3) contain coupling terms that are proportional to the relative drift between the different ions. For a gas with a single major ion, the major ion-minor ion coupling term accounts for the tendency of the major ion to drag the minor ion along as it flows (Schunk and Walker, 1970a, b). In the topside Venus ionosphere, however, it is likely that the lighter, minor $\mathrm{O}^{+}$ion has a flow velocity different from the more massive molecular ions. A downward $\mathrm{O}^{+}$flow might result if the Bauer and Hartle (1974) solar wind-ionosphere interaction mechanism is operating, while an upward $\mathrm{O}^{+}$flow could result if some other interaction mechanism controls the ionopause formation.

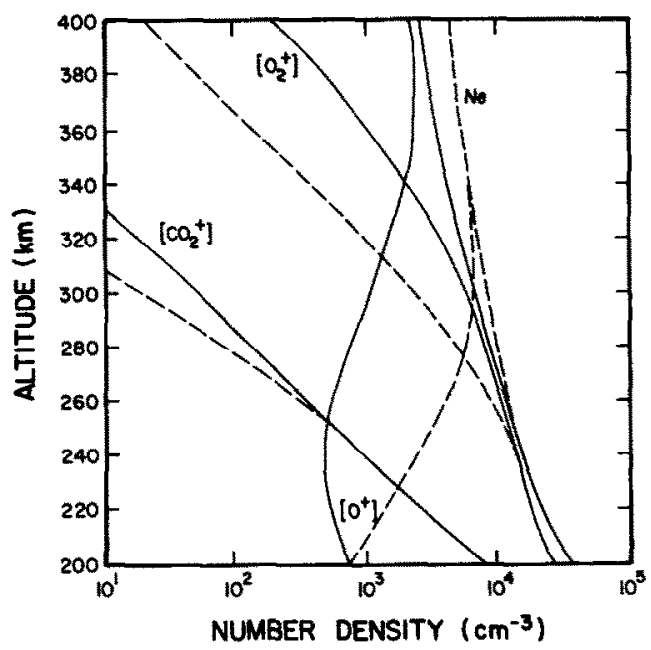

FIG. 5. ION AND ELECTRON DENSITY PROFILES FOR AN UPWARD $\mathrm{O}^{+}$FLUX OF $7 \times 10^{5} \mathrm{~cm}^{-2} \mathrm{sec}^{-1}$.

For these calculations the $\mathrm{CO}_{2}{ }^{+}$and $\mathrm{O}_{2}{ }^{+}$fluxes are zero, and the different ions are assumed to have a common, constant temperature of $350 \mathrm{~K}$. The dashed curves show the profiles that result when the $\mathrm{O}^{+}$flux is set equal to zero.

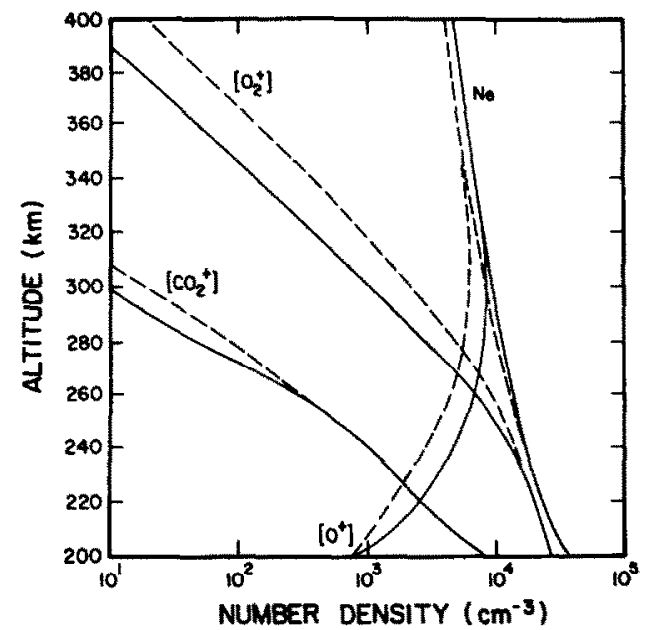

FIG. 6. ION AND ELECTRON DENSTTY PROFILES FOR A DOWNWARD $\mathrm{O}^{+}$FLUX OF $1 \times 10^{6} \mathrm{~cm}^{-2} \mathrm{sec}^{-1}$.

For these calculations the $\mathrm{CO}_{2}^{+}$and $\mathrm{O}_{2}^{+}$fluxes are zero, and the different ions are assumed to have a common, constant temperature of $350 \mathrm{~K}$. The dashed curves show the profiles that result when the $\mathrm{O}^{+}$flux is set equal to zero.

In order to determine the extent to which upward and downward $\mathrm{O}^{+}$fluxes'affect the ion composition, we have calculated ion and electron density profiles for a range of $\mathrm{O}^{+}$fluxes. From this study, we have found that relatively small $\mathrm{O}^{+}$fluxes can appreciably affect the ion composition. Results for upward and downward $\mathrm{O}^{+}$fluxes of $7 \times$ $10^{5} \mathrm{~cm}^{-2} \mathrm{sec}^{-1}$ and $1 \times 10^{6} \mathrm{~cm}^{-2} \mathrm{sec}^{-1}$, respectively, are shown in Figs. 5 and 6 . Also shown in these figures are the density profiles that result when the $\mathrm{O}^{+}$flux is set equal to zero. In generating these figures, we set the molecular ion fluxes to zero and assumed that the different ions have a common temperature of $350 \mathrm{~K}$ at all altitudes. Considering first the upward flow case, it is apparent that an upward $O^{+}$flux of $7 \times 10^{5} \mathrm{~cm}^{-2} \mathrm{sec}^{-1}$ significantly affects the ion composition, with $\mathrm{O}^{+}$reduced and the molecular ions increased at all altitudes. The reduction of $\mathrm{O}^{+}$combined with the increase in $\mathrm{O}_{2}^{+}$ acts to raise the $\mathrm{O}_{2}{ }^{+} / \mathrm{O}^{+}$transition altitude from 280 to $360 \mathrm{~km}$.

Upward $\mathrm{O}^{+}$flow speeds of less than $10 \mathrm{~m} / \mathrm{sec}$ are sufficient to maintain the upward flux of $7 \times$ $10^{5} \mathrm{~cm}^{-2} \mathrm{sec}^{-1}$. However, this flux is close to the critical or limiting $\mathrm{O}^{+}$flux, which is about $7.15 \times$ $10^{5} \mathrm{~cm}^{-2} \mathrm{sec}^{-1}$ for the conditions shown in Fig. 5 . At the critical flux, the $\mathrm{O}^{+}$density decreases with the $\mathrm{O}_{2}{ }^{+}$scale height and, hence, larger upward flow speeds will result from just a slight increase in the magnitude of the upward $\mathrm{O}^{+}$flux. 
Figure 6 indicates that a downward $\mathrm{O}^{+}$flux of about $1 \times 10^{6} \mathrm{~cm}^{-2} \mathrm{sec}^{-1}$ is needed to affect the ion composition in the topside Venus ionosphere. Downward $\mathrm{O}^{+}$flow speeds of only a few $\mathrm{m} / \mathrm{sec}$ are capable of maintaining the downward $\mathrm{O}^{+}$flux of $1 \times 10^{6} \mathrm{~cm}^{-2} \mathrm{sec}^{-1}$.

Although upward and downward $\mathrm{O}^{+}$fluxes of $7 \times 10^{5}$ and $1 \times 10^{6} \mathrm{~cm}^{-2} \mathrm{sec}^{-1}$, respectively, appreciably affect the ion composition they have a relatively small effect on the electron density. This illustrates the insensitivity of the electron density to small $\mathrm{O}^{+}$-molecular ion drift velocity differences.

As a final point on ion flows, we note that if the coupling of the ions through the frictional drag terms is neglected, the major and minor ion diffusion equations take the form

$$
\begin{aligned}
\mathbf{u}_{i}=-D_{i}\left[\frac{1}{n_{i}} \nabla n_{i}-\frac{m_{i} \mathbf{G}}{k T_{i}}\right. & +\frac{1}{T_{i}} \nabla T_{i} \\
& \left.+z_{i} \frac{T_{e} / T_{i}}{n_{e}} \nabla n_{e}+\frac{z_{i}}{T_{i}} \nabla T_{e}\right]
\end{aligned}
$$

where we have neglected thermal diffusion terms so that this equation is directly comparable to diffusion equations used in previous studies of the ionosphere of Venus. Equation (9) resembles the diffusion equation for an ion in a weakly-ionized, stationary gas, except that the diffusion coefficient in equation (9) is determined by Coulomb collisions not ion-neutral collisions. It is not clear what diffusion coefficient has been used in the most recent studies of the Venus ionosphere (Kumar and Hunten, 1974; Nagy et al., 1975), but if the topside Venus ionosphere is truly in diffusive equilibrium the ion-neutral and Coulomb diffusion coefficients yield the same density profiles. However, the use of an ion-neutral diffusion coefficient for the topside Venus ionosphere will result in an incorrect estimate for the magnitude of the ion flux needed to produce departures from diffusive equilibrium. Had we incorrectly used the ion-neutral diffusion coeffcient instead of the Coulomb diffusion coefficient in our study of upward and downward $\mathrm{O}^{+}$flows, we would have obtained the erroneous result that $\mathrm{O}^{+}$ flows of order $1 \times 10^{6} \mathrm{~cm}^{-2} \mathrm{sec}^{-1}$ are too small to affect the ion composition.

\section{Effect of an electron temperature gradient}

Upon looking at the structure of the ion diffusion equations, it is apparent that an electron temperature gradient acts to reduce the electron density scale height if the base electron temperature is low. Since the scale height of the topside electron den-

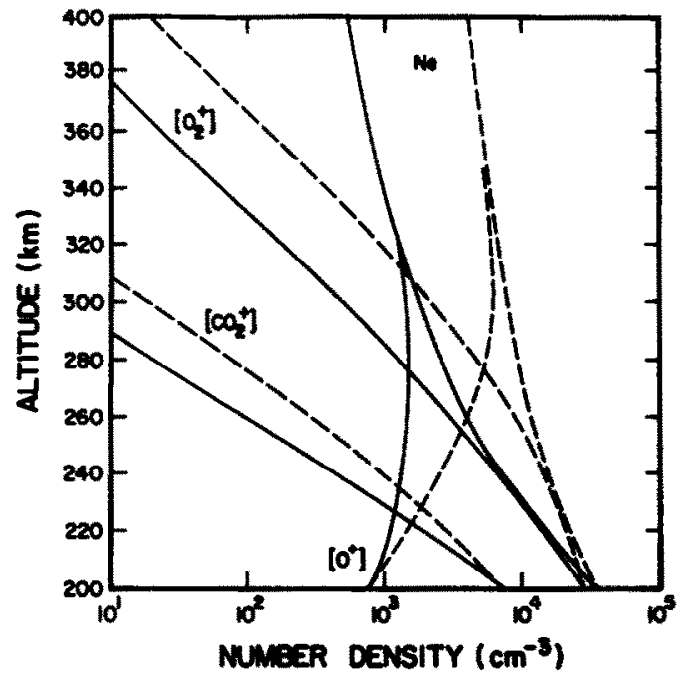

FIG. 7. ION AND ELECTRON DENSTTY PROFILES FOR AN ENHANCED ELECTRON TEMPERATURE GRADIENT.

The electron temperature gradient is $5 \mathrm{~K} / \mathrm{km}$ to $280 \mathrm{~km}$ and zero above. The ions are assumed to have a common, constant temperature of $350 \mathrm{~K}$. The dashed curves show the profiles for the Nagy et al. (1975) electron temperature profile.

sity measured by Mariner 10 is much smaller than that measured by Mariner 5 , it is of interest to determine the extent to which an electron temperature gradient can reduce the scale height. In Fig. 7 , we present ion and electron density profiles for the case where the electron temperature increases with altitude with a $5 \mathrm{~K} / \mathrm{km}$ gradient from a lower boundary temperature of $540 \mathrm{~K}$ at $200 \mathrm{~km}$ to $940 \mathrm{~K}$ at $280 \mathrm{~km}$. Above $280 \mathrm{~km}, \nabla T_{e}=0$. Also shown in this figure are the density profiles for the Nagy et al. (1975) electron temperature profile, which is nearly constant with $T_{e} \approx 2000 \mathrm{~K}$ between 220 and $400 \mathrm{~km}$. For these calculations, we set the ion fluxes to zero and assumed that the different ions have a common temperature of $350 \mathrm{~K}$ at all altitudes. It is apparent that an electron temperature gradient can significantly reduce the electron density scale height over a limited altitude range, but eventually the increasing electron temperature offsets the effect of the electron temperature gradient.

We have also considered various ion temperature gradients in combination with the electron temperature gradient, but as noted earlier the electron density profile is very insensitive to the ion temperature profile. We therefore conclude that the reduced, topside electron density scale height measured by Mariner 10 is probably not a result of an enhanced ion or electron temperature gradient. 
At present, it appears that the solar windionosphere interaction mechanism of Bauer and Hartle (1974) is the likely explanation for the reduced, topside electron density scale height measured by Mariner 10 . With this mechanism, penetrating solar wind plasma compresses the topside ionosphere by inducing a downward $\mathrm{O}^{+}$drift velocity. Nagy et al. (1975) have also been able to fit the Mariner 10 topside electron density profile by assuming an upward plasma flow speed of $10 \mathrm{~km} / \mathrm{sec}$ at $300 \mathrm{~km}$. However, these authors felt that an upward flow of this order of magnitude was unreasonably high. We have a further reason for rejecting this mechanism. In the Nagy et al. model, $T_{i}=350 \mathrm{~K}$ and, therefore, a drift speed of $10 \mathrm{~km} / \mathrm{sec}$ results in an ion Mach number greater than 23. Consequently, the altitude profiles of density and drift velocity are determined by the nonlinear acceleration terms in the ion momentum equations, which were neglected in the Nagy et al. model. For highly supersonic flows, these terms force the density and drift velocity profiles to go constant with altitude (Banks and Holzer, 1969; Marubashi, 1970; Raitt et al., 1975), which is in conflict with the Mariner 10 measurements.

\section{Electron density profile}

From our calculations, we have found that the electron density profile is very insensitive to the ion temperature, the ion temperature gradient, and to

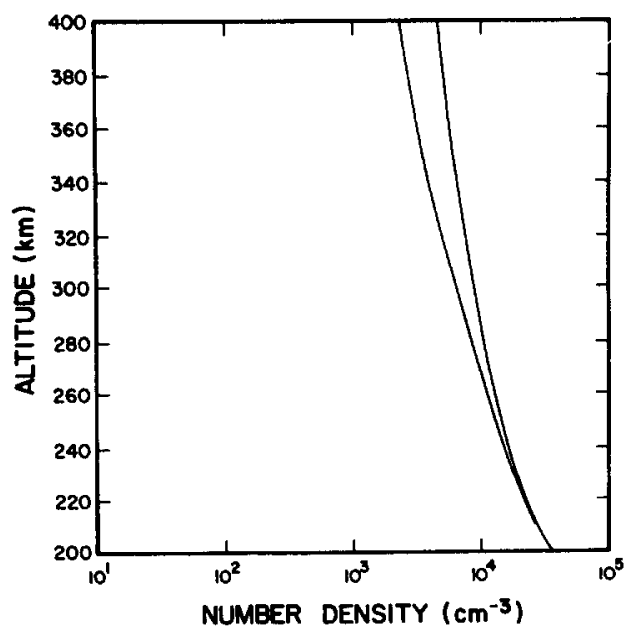

Fig. 8. The RANGe OF ELECTRON DENSITY PROFILES For ALl THE CASES CONSIDERED IN FIGS. 1-6.

This figure illustrates the insensitivity of the electron density profile to a wide range of parameters. relative drifts between the ion species of a few $\mathrm{m} / \mathrm{sec}$. To illustrate this insensitivity, we show in Fig. 8 the range of electron density profiles obtained from all of our calculations, except those dealing with enhanced topside electron temperature gradients. Because of this insensitivity, more extensive measurements of the topside Venus ionosphere will be needed before ionospheric models can obtain definitive information on the processes governing the structure of the topside ionosphere. The insensitivity of the electron density in the topside, terrestrial ionosphere has also been noted by Schunk and Walker (1969) for diffusive equilibrium conditions.

\section{Induced ion heat flow}

Our final discussion deals with the heat flow equations (4)-(6). As noted by St-Maurice and Schunk (1977), a temperature gradient in either major ion gas causes heat to flow in both gases. Also, a relative drift between the major ion gases causes heat to flow in both gases. Similar heat flows also occur in the minor ion gases. In our previous study (St.-Maurice and Schunk, 1977), we have shown that these heat flow processes can have an important influence on the thermal structure of the topside terrestrial ionosphere and, therefore, it is of interest to study their possible importance in the topside ionosphere of Venus.

The importance of the heat flow processes can be determined by comparing the terms in the heat flow equations. This comparison can be done, for example, by setting the relative flow term in the species heat flow equation separately equal to both major ion temperature gradient terms. With this procedure, we not only can determine which temperature gradient term is more important, but we also obtain the magnitude of the relative drift that produces the same heat flow as a given temperature gradient.

The results of such a comparison are shown in Table 2 for the case where $\mathrm{O}^{+}$and $\mathrm{O}_{2}^{+}$are the major ions. In generating this table, we set $T\left(\mathrm{O}^{+}\right)=$ $T\left(\mathrm{O}_{2}{ }^{+}\right)=700 \mathrm{~K}, \nabla T\left(\mathrm{O}^{+}\right)=\nabla T\left(\mathrm{O}_{2}{ }^{+}\right)=1 \mathrm{~K} / \mathrm{km}$ and $n_{e}=3 \times 10^{4} \mathrm{~cm}^{-3}$. Since the drift velocity differences shown in Table 2 are approximately proportional to $T_{s}^{3 / 2} \nabla T_{s} / n_{e}$, where $s=\mathrm{O}^{+}$or $\mathrm{O}_{2}{ }^{+}$, they can be readily scaled to other values of these parameters. In the expression for $q\left(\mathrm{O}_{2}^{+}\right)$, larger $\mathrm{O}^{+}-\mathrm{O}_{2}^{+}$ drift velocity differences are needed to match the $\nabla T\left(\mathrm{O}_{2}{ }^{+}\right)$term than the $\nabla T\left(\mathrm{O}^{+}\right)$term when $\mathrm{O}_{2}{ }^{+}$is the major ion, indicating that the $\nabla T\left(\mathrm{O}_{2}{ }^{+}\right)$term is the dominant temperature gradient term. However, when the $\mathrm{O}_{2}^{+}$and $\mathrm{O}^{+}$densities are comparable or when $\mathrm{O}^{+}$is the dominant ion, an $\mathrm{O}^{+}$temperature 
Table 2. Magnitude of THE $\mathrm{O}^{+}-\mathrm{O}_{2}{ }^{+}$Velocity DifFerENCE $(\mathrm{m} / \mathrm{sec})$ THAT PRODUCES THE SAME HEAT FLOW AS THE INDICATED TEMPERATURE GRADIENT TERM

For this table, $T\left(\mathrm{O}^{+}\right)=T\left(\mathrm{O}_{2}^{+}\right)=700 \mathrm{~K}, \quad \nabla T\left(\mathrm{O}^{+}\right)=$ $\nabla \mathrm{T}\left(\mathrm{O}_{2}{ }^{+}\right)=1 \mathrm{~K} / \mathrm{km}$ and $n_{e}=3 \times 10^{4} \mathrm{~cm}^{-3}$

\begin{tabular}{cccccr}
\hline & \multicolumn{2}{c}{$q\left(\mathrm{O}_{2}{ }^{+}\right)$} & & \multicolumn{2}{c}{$q\left(\mathrm{O}^{+}\right)$} \\
\cline { 2 - 3 } \cline { 5 - 6 }$\left(\mathrm{O}_{2}{ }^{+}\right) / n\left(\mathrm{O}^{+}\right)$ & $\nabla T\left(\mathrm{O}_{2}{ }^{+}\right)$ & $\nabla T\left(\mathrm{O}^{+}\right)$ & & $\nabla T\left(\mathrm{O}_{2}{ }^{+}\right)$ & $\nabla T\left(\mathrm{O}^{+}\right)$ \\
\hline 0.001 & 6.1 & 5.30 & & 0.86 & 2637 \\
0.01 & 6.1 & 5.20 & & 0.87 & 266 \\
0.05 & 6.0 & 4.70 & & 0.88 & 55 \\
0.10 & 5.9 & 4.30 & & 0.91 & 29 \\
0.25 & 5.9 & 3.50 & & 0.97 & 13 \\
0.50 & 6.3 & 2.90 & & 1.05 & 8.1 \\
1.0 & 7.6 & 2.30 & & 1.20 & 5.5 \\
2.0 & 10.6 & 1.96 & & 1.35 & 4.3 \\
4.0 & 16.7 & 1.74 & & 1.50 & 3.6 \\
10.0 & 36.0 & 1.60 & & 1.70 & 3.3 \\
20.0 & 67.0 & 1.54 & & 1.80 & 3.2 \\
100.0 & 32.0 & 1.50 & & 1.80 & 3.1 \\
1000.0 & 315.0 & 1.49 & 1.90 & 3.1 \\
\hline
\end{tabular}

gradient is nearly as effective in driving an $\mathrm{O}_{2}{ }^{+}$heat flow as an $\mathrm{O}_{2}^{+}$temperature gradient. For $q\left(\mathrm{O}^{+}\right)$we find a similar effect in that the dominant temperature gradient term is the $\nabla T\left(\mathrm{O}^{+}\right)$term when $\mathrm{O}^{+}$is the major ion, but when the $\mathrm{O}^{+}$and $\mathrm{O}_{2}{ }^{+}$densities are comparable or when $\mathrm{O}^{+}$is minor both $\mathrm{O}^{+}$and $\mathrm{O}_{2}{ }^{+}$temperature gradients are effective in driving an $\mathrm{O}^{+}$heat flow.

With regard to the ion heat flow induced by an $\mathrm{O}^{+}-\mathrm{O}_{2}{ }^{+}$relative drift, the larger numbers for a given $q$ indicate the relative drift that is needed for this process to match the heat flow induced by the dominant temperature gradient term. For $\mathrm{O}^{+}$, an $\mathrm{O}^{+}-\mathrm{O}_{2}{ }^{+}$relative drift of only a few $\mathrm{m} / \mathrm{sec}$ induces an $\mathrm{O}^{+}$heat flow equivalent to a $1 \mathrm{~K} / \mathrm{km}$ temperature gradient, if the $\mathrm{O}^{+}$density is comparable to or smaller than the $\mathrm{O}_{2}{ }^{+}$density. Likewise, for $\mathrm{O}_{2}{ }^{+}$we find that an $\mathrm{O}^{+}-\mathrm{O}_{2}^{+}$relative drift of less than $10 \mathrm{~m} / \mathrm{sec}$ is equivalent to a $1 \mathrm{~K} / \mathrm{km}$ temperature gradient when the $\mathrm{O}_{2}{ }^{+}$density is comparable to or smaller than the $\mathrm{O}^{+}$density. Relative drifts between the different ion species of this order of magnitude occur in the topside terrestrial ionosphere for various reasons (Bailey et al., 1973; Vickrey et al., 1976), and it is likely that they also occur in the topside Venus ionosphere, particularly if the solar wind-ionosphere interaction mechanism of Bauer and Hartle (1974) is operating. The convergence or divergence of the heat flow induced by a relative drift between the different ions could have an important influence on the thermal structure of the topside Venus ionosphere.

\section{SUMMARY}

We have studied the extent to which certain transport processes affect the structure of the topside Venus ionosphere. In particular, we have obtained daytime, steady-state profiles of ion and electron density from 200 to $400 \mathrm{~km}$ for a range of topside conditions. Our choice of lower boundary ion densities was motivated by the theoretical study of Nagy et al. (1975), which indicated that $\mathrm{O}_{2}{ }^{+}$was the dominant ion at $200 \mathrm{~km}$.

From our study we have found:

(1) The ion temperature has a significant influence on the ion composition, but a negligible influence on the electron density profile.

(2) An $\mathrm{O}^{+}$temperature gradient has a larger effect on the ion composition than does a temperature gradient in either of the molecular ion gases.

(3) Thermal diffusion may have an appreciable effect on the ion density profiles if the ion temperature gradients are larger than about $3 \mathrm{~K} / \mathrm{km}$.

(4) An enhanced electron temperature gradient over an extended altitude range in combination with a low base electron temperature acts to lower significantly the electron density scale height in the $200-300 \mathrm{~km}$ altitude range, but the reduction is not sufficient to explain the Mariner 10 data.

(5) Coulomb collisions are more important than ion-neutral collisions in the topside Venus ionosphere and, therefore, the plasma is effectively fullyionized.

(6) An upward $\mathrm{O}^{+}$flux of $7 \times 10^{5} \mathrm{~cm}^{-2} \mathrm{sec}^{-1}$ is close to the critical $\mathrm{O}^{+}$flux for our lower boundary $\mathrm{O}^{+}$density $\left(7.9 \times 10^{2} \mathrm{~cm}^{-3}\right)$. Since $\mathrm{O}_{2}^{+}$is the dominant species impeding the upward flow of $\mathrm{O}^{+}$, at the critical flux the $\mathrm{O}^{+}$density falls off with the $\mathrm{O}_{2}{ }^{+}$ scale height.

(7) Downward $\mathrm{O}^{+}$fluxes of about $1 \times$ $10^{6} \mathrm{~cm}^{-2} \mathrm{sec}^{-1}$ appreciably affect the ion composition, but have a small effect on the electron density.

(8) Upward $\mathrm{O}^{+}$fluxes and enhanced ion temperatures act to raise the $\mathrm{O}^{+}-\mathrm{O}_{2}{ }^{+}$transition altitude and, thereby, act to maintain $\mathrm{O}_{2}^{+}$as the dominant topside ion.

(9) A relative drift between the ion species of only a few $\mathrm{m} / \mathrm{sec}$ induces an ion heat flow equivalent to a $1 \mathrm{~K} / \mathrm{km}$ temperature gradient.

One of the more important results that we have obtained is that the electron density profile in the topside Venus ionosphere is relatively insensitive to the ion temperature profile and to relative drifts between the different ions of a few $\mathrm{m} / \mathrm{sec}$. On the other hand, the ion composition is sensitive to these parameters. Consequently, at present it is not likely 
that ionospheric models will yield definitive information on the ion composition, the thermal structure or the flow conditions in the topside Venus ionosphere, since only electron density profiles are currently available for testing model predictions.

Acknowledgements-This research was supported, in part, by NSF Grant ATM76-19792 at Utah State University and, in part, by NSF Grant ATM74-21090 AO2 at the University of Michigan.

\section{REFERENCES}

Bailey, G. J., Moffett, R. I., Hanson, W. B. and Sanatani, S. (1973). Effects of interhemisphere transport on plasma temperatures at low latitudes. J. geophys. Res. 78, 5597-5610.

Banks, P. M. and Holzer, T. E. (1969). High-latitude plasma transport: the polar wind. J. geophys. Res. 74, $6317-6332$.

Bauer, S. J. and Hartle, R. E. (1974). Venus ionosphere: an interpretation of Mariner 10 observations. Geophys. Res. Lett. 1, 7-9.

Burgers, J. M. (1969). Flow Equations for Composite Gases. Academic Press, New York.

Eshleman, V. R., Fjeldbo, G., Anderson, J. D., Kliore, A. and Dyce, R. B. (1967). Venus: ionosphere and atmosphere as measured by dual-frequency radio occultation of Mariner 5. Science 158, 1678-1682.

Fjeldbo, G., Seidel, B., Sweetnam, D. and Howard, T. (1975). The Mariner 10 radio occultation measurements of the ionosphere of Venus. J. atmos. Sci. 32, 1232-1236.

Herman, J. R., Hartle, R. E. and Bauer, S. J. (1971). The dayside ionosphere of Venus. Planet. Space Sci. 19, 443-460.

Howard, H. T. et al. (1974). Venus: mass, gravity field, atmosphere and ionosphere as measured by the Mariner 10 dual-frequency radio system. Science 183, 1297-1301.

Kliore, A. J., Levy, G. S., Cain, D. L., Fjeldbo, G. and Rasool, S. I. (1967), Atmosphere and ionosphere of Venus from Mariner $5 \mathrm{~S}$-band radio occultation experiment. Science 158, 1683.
Kumar, S. and Hunten, D. M. (1974). Venus: an ionospheric model with and exospheric temperature of 350 K. J. geophys. Res. 79, 2529-2532.

Liu, S. C. and Donahue, T. M. (1975). The aeronomy of the upper atmosphere of Venus. Icarus 24, 148-156.

Marubashi, K. (1970). Escape of the polar-ionospheric plasma into the magnetospheric tail. Rep. Ionosph. Space Res. Japan 24, 322-346.

McCormick, P. T., Michelson, P. F., Pettibone, D. W. and Whitten, R. C. (1976). On the energy deposition of photoelectrons in the atmosphere of Venus. $J$. geophys. Res. 81, 5196-5200.

McElroy, M. B. (1968). The upper atmosphere of Venus in the light of the Mariner 5 measurements. J. atmos. Sci. 25, 574-577.

McElroy, M. B. and McConnell, J. C. (1971). Atomic carbon in the atmospheres of Mars and Venus. $J$. geophys. Res. 76, 6674-6690.

Nagy, A. F., Liu, S. C., Donahue, T. M., Atreya, S. K. and Banks, P. M. (1975). A model of the Venus ionosphere. Geophys. Res. Lett. 2, 83-86.

Raitt, W. J., Schunk, R. W. and Banks, P. M. (1975). A comparison of the temperature and density structure in high and low speed thermal proton flows. Planet. Space Sci. 23, 1103-1117.

St.-Maurice, J.-P. and Schunk, R. W. (1977). Diffusion and heat flow equations for the mid-latitude topside ionosphere. Planet. Space Sci. 25, 907.

Schunk, R. W. (1975). Transport equations for aeronomy. Planet. Space Sci. 23, 437-485.

Schunk, R. W. and Walker, J. C. G. (1969). Thermal diffusion in the topside ionosphere for mixtures which include multiply-charged ions. Planet. Space Sci. 17, 853-868.

Schunk, R. W. and Walker, J. C. G. (1970a). Thermal diffusion in the $F_{2}$-region of the ionosphere. Planet. Space Sci. 18, 535-557.

Schunk, R. W. and Walker, J. C. G. (1970b). Minor ion diffusion in the $F_{2}$-region of the ionosphere. Planet. Space Sci. 18, 1319-1334.

Vickrey, J. F., Swartz, W. E. and Farley, D. T. (1976). Incoherent scatter measurements of ion counterstreaming. Geophys. Res. Lett. 3, 217-220.

Whitten, R. C. (1969). Thermal structure of the ionosphere of Venus. J. geophys. Res. 74, 5623-5628. 